\title{
The power of interest: minoritized women's interest in engineering fosters persistence beliefs beyond belongingness and engineering identity
}

Dina Verdín(1)

\begin{abstract}
Backgrounds: This study examined how developing an engineering identity through the interplay between interest, recognition, and performance/competence beliefs and establishing a sense of belonging supported women's persistence beliefs in engineering. Persistence belief in this study is captured through women's certainty of graduating with an engineering degree. Students' levels of motivation, affective states, and actions are based on what students believe to be true. Data were gathered from a survey administered to engineering students at nine institutions across the USA. Only female engineering students were used in the analysis. Students were further grouped into categories based on the representation of their race/ethnicity in engineering; 121 women were identified as minoritized in engineering, and 252 were identified as part of the majority group in engineering. Structural equation modeling was used to understand how the development of an engineering identity and modes of belonging (i.e., belonging in the major and in the classroom environment) supported women's certainty to graduate with an engineering degree. All latent constructs were examined for measurement invariance; partial measurement invariance was achieved. Equality constraints on the structural paths of the model were not enforced to allow for differences across groups.

Results: Seeing oneself as an engineer (i.e., internal recognition) did not support minoritized women's certainty to persist toward degree completion, whereas this internal recognition supported majority women's persistence. Belonging in the major and belonging in the classroom environment did not support minoritized women's certainty to persist. Establishing a sense of belonging in the classroom environment supported majority women's certainty to persist. Minoritized women's persistence toward degree completion was supported by their interest in engineering and their confidence in performing well in engineering coursework. However, interest in engineering was two times more influential toward minoritized women's persistence than their performance competence beliefs.

Conclusion: These findings provide educators with a nuanced understanding of how identity development and modes of belonging differentially affect women's persistence beliefs. These findings suggest that educators need to understand the powerful influence minoritized women's interest in engineering has on their persistence beliefs and create mechanisms to continuously reinforce interest.
\end{abstract}

Keywords: Belonging, Minoritized women, Engineering identity, Interest, Structural equation modeling

Correspondence: dina.verdin@asu.edu

Arizona State University, Mesa, AZ, USA

Springer Open (c) The Author(s). 2021 Open Access This article is licensed under a Creative Commons Attribution 4.0 International License, which permits use, sharing, adaptation, distribution and reproduction in any medium or format, as long as you give appropriate credit to the original author(s) and the source, provide a link to the Creative Commons licence, and indicate if changes were made. The images or other third party material in this article are included in the article's Creative Commons licence, unless indicated otherwise in a credit line to the material. If material is not included in the article's Creative Commons licence and your intended use is not permitted by statutory regulation or exceeds the permitted use, you will need to obtain permission directly from the copyright holder. To view a copy of this licence, visit http://creativecommons.org/licenses/by/4.0/. 


\section{Introduction}

Developing an identity as an engineer and feeling a sense of belonging in an engineering academic pathway has been repeatedly emphasized in prior literature to have a significant impact on students' persistence (Geisinger \& Raman, 2013; Godwin \& Potvin, 2017; Marra et al., 2012; Pierrakos et al., 2009). Additionally, establishing a sense of belonging is important toward supporting students' ability to cope with difficult situations (Vaz et al., 2015), supports motivation (Baumeister \& Leary, 1995; Goodenow, 1993), and engagement in one's campus culture (Larson, 2000; Wilson et al., 2015). However, the historical roots and persistent masculinity of engineering make it challenging to establish a sense of belonging or identification with the field for women, as their presence in the discipline is often met with opposition (Bix, 2004; Slaton, 2015). Women in engineering are more often navigating a culture that views their participation as others in a "male territory" (Bix, 2004, p. 28; Slaton, 2015), as outsiders (Tate \& Linn, 2005; Watts, 2009), or as simply not belonging in the field (Foor et al., 2007; Tonso, 1996, 1999, 2007). In a study ascertaining ways of belonging in engineering, women were more likely to describe men as belonging to engineering because they were "book smart," "technical" thinkers," and "socially awkward," thus fitting the stereotype of an engineer (Benedict, Verdín, Baker, Godwin, \& Milton, 2018, p. 12). More so, women from diverse backgrounds face a double bind. They are minoritized in engineering based on their gender and race/ethnicity both in engineering and in the broader institutional culture of higher education (Ong et al., 2011). Minoritized students consistently receive messages that an engineer is a certain type of person. Take, for example, CBS's comedy The Big Bang Theory, which features the lives of four nerdy, hyperlogical, introverted men in STEM-related professions. While there is no one way of being an engineer, there is a lack of diverse representation and recognition of who can do and who can be in engineering (Benedict, Verdín, Baker, Godwin, \& Milton, 2018). It is not only popular TV shows that depict a certain way of being like an engineer; the engineering culture for decades has been a "prototypical masculine profession" defined by a White, Western male perspective (Jorgenson, 2002, p. 351). Institutions of higher education are also historically situated through a "White cultural ideology," perpetuating hostile and chilly climates through a White mainstream ideology which "sustain[s] the structure of domination and oppression [by] allow[ing] institutional policies and practices to be seen as unproblematic" (Gusa, 2010, p. 465). Taken together, the culture of engineering and institutions of higher education maintain racialized environments that disrupt minoritized students' sense of belonging (e.g., Foor et al., 2007; Holland, 2019; Hurtado
\& Carter, 1997; Johnson et al., 2007; Walton \& Cohen, 2007).

Holland's (2019) examination of students who persisted or switched out of STEM fields found that belongingness issues were most prevalent among minoritized students. Similar findings can be found in Foor et al.'s (2007) ethnographic study of Inez, a minoritized student pursuing an engineering degree, who summed up her narrative statement, "I just wish that I belonged more in this whole engineering group, with the students and the teachers ..." (p. 104). In another study, Bianca's lack of in-group peers in her chemical engineering courses hindered her sense of belonging, stating, "Sometimes I feel like I don't belong... I'm the only Hispanic girl there, so you turn around, and you try to find someone that you feel comfortable ... I don't feel that connection, that bond, so I feel like I'm alone" (Verdín \& Godwin, 2018a, p. 277). While Inez persisted in completing her engineering degree, Bianca chose to switch out of engineering into a field where she felt a sense of belonging (Verdín \& Godwin, 2018a). Although not explicitly cited in the article by Foor et al. (2007), I hypothesize that Inez was able to successfully navigate engineering, despite many challenges and lack of belonging, because she was able to see herself in the role of being an engineer (i.e., identity development) and positioned herself accordingly.

Success in engineering can thus be understood as integration into the engineering culture. The integration process is centered around identifying as someone that can do or become an engineer (Foor et al., 2007). Scholars have theorized that identity development and feeling a sense of belonging are intimately related (Meyers et al., 2012; Osterman, 2000; Tonso, 2007). However, there is a gap in our understanding of how, empirically, the development of an engineering identity and sense of belonging, together, inform persistence in engineering. Drawing on prior scholarship and Inez's powerful experience, I hypothesize that identity is important to students' belongingness and persistence in engineering. Therefore, this study empirically examines how authoring an engineering identity impacts minoritized students' certainty to persist toward degree completion.

\section{Minoritization: the process of being minoritized}

Even though engineering remains a male-dominated field with less than $22 \%$ of degrees awarded to women in the USA, women who identify as Black/African American, Latina, Native American/Alaska Native, or Native Hawaiian/Pacific Islander earn fewer degrees in engineering compared to Asian/Asian American and White students (Roy, 2018; Yoder, 2017). Only 2.3\% and 1\% of engineering degrees were awarded to Latinas and Black/ African American women, respectively (National Science 
Foundation \& National Center for Science and Engineering Statistics, 2019c). An earlier report by the same institutions cited that "in the past 2 decades" Native Americans and/or Alaska Natives "have earned about 1\% of the bachelor's degrees in each of the broad science and engineering fields" (National Science Foundation \& National Center for Science and Engineering Statistics, 2017, p. 8). Additionally, the National Science Foundation documented in 2017 that among trained scientists and engineers, Black/African American and Latino/as had higher percentages of unemployment compared to Asian and White individuals (National Science Foundation \& National Center for Science and Engineering Statistics, 2019d). Additionally, Asian and White women trained as scientists and engineers were employed at a higher percentage compared to Black/African American, Latinas, Native American or Alaska Native, Native Hawaiian or Other Pacific Islander, and multi-racial women (National Science Foundation \& National Center for Science and Engineering Statistics, 2019a). Reports acknowledge that White and Asian women are more represented in engineering compared to other racial/ethnic groups (e.g., National Science Foundation \& National Center for Science and Engineering Statistics, 2019d; Roy, 2018). Considering these reports, one can conclude that women from certain racial/ethnic groups (i.e., Black/African American, Latina, Native American/Alaska Native, Native Hawaiian/Pacific Islander) are further minoritized in engineering.

The term minoritized is used to refer to an "objective outcome, experienced by "minority" racial-ethnic groups, of the exclusionary practices of more dominant groups resulting from historical and contemporary racism" (Chase et al., 2014, p. 671). An examination of how institutions of higher education perpetuate a color-blind ideology that reproduces exclusionary practices for minoritized students can be found through the work of Gusa (2010), McGee (2016), Museus et al. (2015), and Reason and Evans (2007), to name a few. Ong et al.' (2011) seminal article, Inside the Double Bind, rationalized that Asian/Asian American women are an underrepresented group because their status has not reached "advanced levels of upper management and leadership in STEM academia [and] industry" (p. 181). However, researchers argue that specific Asian/ Asian American subpopulations are not minoritized in engineering in the same way as other women of color. For example, Museus (2013) and Museus et al. (2015) emphasized the inequalities among Asian/Asian Americans' broad categorization, highlighting the disparities between certain Southeast Asians and Asians from the geographic East and South regions. Asian/Asian American subpopulations from the East and South were found to have higher annual income, educational attainment levels, and lower rates of poverty than people from minoritized backgrounds (including Southeast Asians; Museus et al., 2015).
The higher representation of White and Asian/Asian American (i.e., geographic East and South) are not only seen in undergraduate engineering programs or engineering industry; the university engineering faculty demographic is largely comprised of men and women who identify as White and Asian/Asian American (Beutel \& Nelson, 2005; National Science Foundation \& National Center for Science and Engineering Statistics, 2019b). Notably, the percentage of Asian/Asian American women granted Full Professor's status in engineering compares to White women (Beutel \& Nelson, 2005). Although reports from the National Science Foundation do not provide more detailed data of ethnic subpopulations, based on the extensive research by Museus (e.g., Museus, 2013; Museus et al., 2015; Museus \& Kiang, 2009), one may infer that the largest Asian ethnic subgroup populations in engineering are from the East and South regions. Thus, mindful of the disparities between Asian ethnic subpopulations, in this study students' identifying with a Southeast background are considered minoritized students in engineering.

While women of all race/ethnicities may experience implicit and explicit biases based on their gender, given the reality that women are underrepresented in engineering, there are advantages afforded to women in non-stigmatized groups or groups with higher representation in engineering. Asian and White women may experience privilege in engineering due to being part of the majority racial/ethnic group or being part of the racial/ethnic in-group. Goodman (2011) describes privilege as benefits or advantages "systematically afforded [to] people from dominant groups simply because of their social group membership" (p. 18). In light of these findings, I examine how women's certainty to persist toward degree completion is differentially informed based on membership (i.e., women in the majority group and those who are minoritized in engineering). Throughout this study, women who are part of the racial/ethnic majority in engineering are referred to as majority women, while women who are part of the racial/ethnic minority group in engineering are referred to as minoritized women.

\section{Objective}

The objective of this study was to broadly understand how developing an engineering identity and modes of belonging support minoritized women and majority women's persistence in engineering. To achieve the objective, I drew from the experience of Inez to empirically model relationships between engineering identity, belongingness, and persistence beliefs. Specifically, I answered the following research questions,

RQ1. What is the relationship between engineering identity and modes of belonging for minoritized and majority women? 
RQ 2. Does developing an engineering identity and establishing a sense of belonging support minoritized women and majority women's belief about persisting in engineering?

I used the frameworks of engineering identity (i.e., comprising of interest, internal and external recognition, and performance/competence beliefs) and modes of belonging (i.e., belonging in the major and classroom) to understand women's belief about persisting. First, I examine how the engineering role identity constructs of interest, recognition, and performance/competence directly impact modes of belonging. An item capturing students' certainty of graduating with an engineering degree was used as a proxy for persistence beliefs. Certainty is conceptualized as the degree of confidence or determination an individual has about their career decision (e.g., graduating with an engineering degree; Hartung, 1995). Students' determination of graduating with a degree in a given field is related to career options they will consider, that is, students certainty about persisting toward graduation is part of the career development process (Betz \& Hackett, 1986; Lent et al., 1994, 2003). In this study, I examine one aspect of the career development process: women's certainty of graduating with an engineering degree, which I refer to as persistence beliefs. Persistence beliefs in this study is captured through women's certainty of graduating with an engineering degree, as "level of motivation, affective states, and actions are based more on what [students] believe" (Bandura, 1997, p. 2).

\section{Theoretical framing}

\section{Authoring an engineering role identity}

"[I]dentities serve as behavioral guides," that is, the behaviors that people engage in through their new roles or interactions are "critical elements in helping individuals define themselves as occupants of a particular position" (Burke et al., 2003, pp. 42-43). In the education literature, identity is defined as "being recognized as a certain 'kind of person,' in a given context" (Gee, 2001, p. 99). Authoring a role identity in the engineering context is a recursive, socially constructed process that is framed through (1) interest in the context, (2) internal and external recognition, and (3) demonstrating one's competence through social performance (Carlone \& Johnson, 2007; Cribbs et al., 2015; Godwin, 2016; Godwin et al., 2016; Godwin \& Kirn, 2020; Hazari et al., 2010; Verdín, Godwin, et al., 2019; Verdín, Godwin, \& Ross, 2018).

Interest plays a crucial role in understanding identity development; it involves a personal desire for learning and knowledge acquisition in a disciplinary context (e.g., engineering; Hazari et al., 2010). Interest can be understood as a psychological state with affective and cognitive factors with focused attention on particular content and/or an "enduring predisposition to re-engage [with] particular classes of objects, events, or ideas" (Ainley et al., 2002; Hidi \& Renninger, 2006; Renninger \& Hidi, 2002, p. 174). Hidi and Renninger (2006) found that interest positively influences persistence and effort, motivation, and learning in the classroom and develops through interactions in the students' environment.

Recognition is both an external manifestation and an internal state required for identity development (Carlone \& Johnson, 2007; Potvin \& Hazari, 2013). Gee (2001) noted that one's identity becomes an identity when "they are recognized by [themselves] or others" (p. 102) in a particular context. However, how people (i.e., peers, instructors, or family members) perceive an individual is an incomplete representation of how she perceives herself; that is, it is equally important to understand how a student internalizes these beliefs in shaping who they are and how they position themselves in the world (i.e., internal recognition; Godwin et al., 2016; Potvin \& Hazari, 2013). Therefore, part of being recognized as an engineer encompasses internalizing the external recognition of being an engineer, i.e., I see myself as an engineer.

Lastly, an individual cannot be recognized as a certain kind of person unless he/she makes visible (i.e., performs) their competence in particular domains (e.g., mathematics, physics, or engineering; Carlone \& Johnson, 2007). Beliefs about performing well and understanding content material have considerable overlap with self-efficacy beliefs. Performance/competence beliefs are global or more general attitudes regarding one's capabilities (Godwin et al., 2016; Potvin \& Hazari, 2013). In comparison, self-efficacy beliefs are both task- and situation-specific but critical in determining how knowledge and skills are acquired (Bandura, 1989; Pajares, 1997). However, "perceived self-efficacy is an important contributor to performance accomplishments, whatever the underlying skills might be" (Bandura, 1997, p. 37). Self-efficacy is generally assessed at the microanalytic level (Pajares, 1997); for example, students can have selfefficacy beliefs in acquiring the skills to solve differential equations, balance chemical equations, or apply the laws of motion. These micro-level skills can be in harmony with students' claims toward understanding and performing well in mathematics, physics, and engineering domains. Prior work has found undergraduate students conceptualize performance and competence beliefs similarly (Cribbs et al., 2015; Potvin \& Hazari, 2013), thus rather than appearing as separate constructs; they appear together.

Collectively, the identity shaping constructs of interest, recognition, and performance/competence beliefs have been used to understand students' decision to pursue an engineering degree (Godwin et al., 2016; Verdín, Godwin, Sonnert, \& Sadler, 2018), career aspirations (i.e., 
engineering industry or entrepreneurial ventures; Rohde et al., 2019; Verdín \& Godwin, 2017a), and their role in fostering a disposition to persevere (Verdín, Godwin, et al., 2019). However, there is still a gap in our understanding of how these identity shaping mechanisms support women's different modes of belonging and belief about persisting in engineering.

\section{Modes of belonging}

Individuals are naturally drawn toward establishing and sustaining a sense of belonging; it has been described as a necessary human motivation (Baumeister \& Leary, 1995). The definition used for belongingness or sense of belonging in college is borrowed from the work of Strayhorn (2018), who stated,

[a] sense of belonging refers to students perceived social support on campus, a feeling or sensation of connectedness, the experiences of mattering or feeling cared about, accepted, respected, valued by, and important to the group (e.g., campus community) or others on campus (e.g., faculty, peers; p. 17).

Vaccaro and Newman (2016), using a constructionist grounded theory approach to define and make meaning of minoritized and privileged students' perceptions of belonging, found common themes of belonging were "feeling comfortable," "fitting in," establishing relationships with people on campus (p. 931). However, minoritized students, in their study, were the only ones to describe belongingness as being respected and being in a safe environment, while privileged students more often described belonging as "fun" and "friendly" (Vaccaro \& Newman, 2016, p. 932). Strayhorn's (2018) definition of belongingness is most aligned with minoritized students' definitions of belonging, and this definition is further evidence in the study by Vaccaro and Newman (2016). Hurtado and Carter (1997) found that a hostile racial campus culture negatively impacted minoritized students' sense of belonging.

Belongingness is most significant in environments such as engineering classrooms or programs where minoritized students experience different and unfamiliar situations or where they are more "likely to feel marginalized, unsupported or unwelcomed" (Strayhorn, 2018, p. 4). A sense of belonging is present in multiple domains, for example, belonging to one's university community and/or belonging in the classroom setting (Smith et al., 2012). Chiu et al. (2016) stated that "context is important to a person's sense of belonging" (p. 176), and understanding sense of belonging in context is necessary. Therefore, it is essential to understand the distinction between students' sense of belonging in engineering and their sense of belonging in their engineering classroom. This study examines both modes of belonging in their influence on women's belief about persisting in engineering.

\section{Method}

Data for this study came from students enrolled in nine different, 4-year ABET-accredited institutions in the US west, south, and mountain regions in Fall 2018. This study focuses exclusively on students who described their gender identity as female $(n=373)$. Students were grouped into categories based on the race/ethnicity representation in engineering. Women who are minoritized in engineering include certain Asian groups, Black/African American, Latina, Native American/Alaska Native, Native Hawaiian/Pacific Islander, Middle Eastern, or another race/ethnicity $\left(n_{1}=121\right)$. Specifically, women who identified with an Asian/Asian American ethnic subpopulation described by Museus (2013) as more likely to experience challenges in higher education were grouped into the minoritized category (e.g., Cambodian, Cantonese, Thai, and Vietnamese). Women who indicated they were White or Asian/Asian American were classified into the majority group $\left(n_{2}=252\right)$. Asian/Asian American women categorized as majority group members included those who only indicated Asian or indicated they were of East or South Asian descent. Additional demographic information on the student sample can be found in Table 1.

In the group categorized as minoritized women, individuals may simultaneously identify as Asian and an additional race/ethnicity or White and an additional race/ethnicity, inflating the race/ethnicity percentage values in Table 1 . However, data were not duplicated; while students may simultaneously identify as Black/African American and Asian, they were placed into the minoritized student group. Students who identified as both White and a minoritized race/ethnic group were categorized into the minoritized group only. Students in the majoritized group consist of the following: (1) students who identify as White and no other race/ethnicity, (2) students who identify as White and Asian from East or South Asian descent, and (3) Asian students who did not explicitly state they were Cambodian, Cantonese, Thai, or Vietnamese. Categorizing students into broader categories of minoritized and majoritized groups does come with a limitation, precisely, the inability to understand the interplay between identity and modes of belonging for specific subpopulations. Nevertheless, this approach provides a first step toward understanding how identity and modes of belonging support persistence beliefs for women who face a double-bind in engineering. 
Table 1 Demographics of women in engineering used in this study

\begin{tabular}{lll}
\hline & $\begin{array}{l}\text { Minoritized } \\
\text { women }\end{array}$ & $\begin{array}{l}\text { Majority } \\
\text { women }\end{array}$ \\
\hline $\begin{array}{l}\text { Total number of students } \\
\text { Race/Ethnicity }\end{array}$ & $121(32 \%)$ & $252(68 \%)$ \\
Asian & $16(13 \%)$ & $89(35 \%)$ \\
Black or African American & $19(16 \%)$ & 0 \\
Latina or Hispanic & $80(61 \%)$ & 0 \\
Middle Eastern or Native African & $11(9 \%)$ & 0 \\
Native American or Alaska Native & $3(2 \%)$ & 0 \\
$\begin{array}{l}\text { Native Hawaiian or another Pacific } \\
\text { Islander }\end{array}$ & $5(4 \%)$ & 0 \\
White & $22(18 \%)$ & $172(68 \%)$ \\
$\begin{array}{l}\text { Another race/ethnicity not listed } \\
\text { above }\end{array}$ & $3(2 \%)$ & 0 \\
Parents' level of education & & $73(28 \%)$ \\
$\begin{array}{l}\text { First-generation college students } \\
\text { Continuing-generation college }\end{array}$ & $78(69 \%)$ & $187(72 \%)$ \\
students & $35(31 \%)$ & $60(23 \%)$ \\
Year enrolled in college & & $109(42 \%)$ \\
$\begin{array}{l}\text { First-year } \\
\text { Second-year }\end{array}$ & $17(15 \%)$ & $49(19 \%)$ \\
Third-year & $16(14 \%)$ & $42(16 \%)$ \\
Fourth-year or higher & $33(29 \%)$ & $47(42 \%)$ \\
\hline
\end{tabular}

${ }^{a}$ Students were given the opportunity to mark all that apply for their race/ ethnicity classification, this table represents students who identified with a single group and those who marked more than one race/ethnicity or marked multiple race/ethnicities

\section{Survey instruments}

The survey instruments used in this study were engineering role identity (Godwin, 2016) and modes of belonging (Verdín, Godwin, Kirn, et al., 2018). The engineering identity measures include three items measuring interest, two items measuring recognition, and four items measuring performance/competence. Students were asked to rate their level of agreement; their responses were measured on a seven-point anchored numeric scale ranging from 0- "Strongly disagree" to 6"Strongly agree." A single item was used to capture students' overall engineering identity, "I see myself as an engineer" and this item was measured using a seven-point anchored numeric scale ranging from 0- "Strongly disagree" to 6- "Strongly agree." Using the indicator of I see myself as an engineer to capture students' overall identification as an engineer is consistent with prior published work (e.g., Godwin, 2016; Godwin \& Kirn, 2020; Verdín, Godwin, et al., 2019; Verdín \& Godwin, 2018b). Responses for belonging in the major and belonging in the classroom were measured on a seven-point anchored numeric scale ranging from 0- "Not at all" to 6- "Very much so." Two belongingness measures were used: belonging in the engineering major (two survey items) and belonging in the engineering classroom (three survey items). Prior work has shown strong validity evidence for the variables of engineering identity (Godwin, 2016; Verdín, Godwin, et al., 2019) and modes of belonging (Boone \& Kirn, 2016; Smith et al., 2012; Verdín, Godwin, Kirn, et al., 2018). Lastly, a single measure was used to examine students' certainty to persist in engineering, "I feel certain about graduating with an engineering degree." Students were asked to rate their level of agreement or disagreement with the statement using a scale of 0- "Completely disagree" to 6- "Completely agree."

\section{Data analysis procedure}

The data analysis procedure implemented in this study is summarized in five steps, (1) assumptions of univariate and multivariate normality were examined, (2) the measurement model was examined through confirmatory factor analysis, (3) measurement invariance across the two groups of minoritized and majority women was examined, (4) structural invariance was purposefully not imposed on the model, and (5) structural equation model fit indices were evaluated. Following the five steps, I conducted a post hoc analysis using a Welch's $t$ test to understand the mean differences between minoritized and majority women. For the Welch's $t$ test, where appropriate, latent constructs were created into composite scores. A false discovery rate (FDR) adjusted $p$ value for multiple comparisons was used to control for possible type 1 error (Benjamini \& Hochberg, 1995). FDR controls for the proportion of incorrectly identified mean differences (i.e., incorrectly rejected null hypotheses). FDR is "more powerful than comparable procedures which control the traditional familywise error rate" (Benjamini \& Yekutieli, 2001, p. 1164). Using Cohen's $d$ statistic, the effect size is reported to interpret the magnitude of the difference between groups, where $0.2 \leq d<0.5$ is small, $0.5 \leq d<0.8$ is medium, and $0.8 \leq$ $d$ is large.

The following model fit indices were used to evaluate model fit, chi-square goodness of fit, comparative fit index (CFI; acceptable values above 0.90 (Bentler, 1990)), Tucker Lewis index (TLI; acceptable values above 0.90 (Bentler, 1990)), root mean square error of approximation (RMSEA; values less than 0.08 indicating moderate fit (Browne \& Cudeck, 1993)), and standardized root mean square residual (SRMR; acceptable value is less than 1, where 0.0 would indicate perfect fit (Brown, 2015; Hu \& Bentler, 1999)). The confirmatory factor analysis was run using the $c f a$ function and the measurement invariance test and structural equation model were run using the sem function found in the lavaan package (Rosseel, 2012). All analyses were 
conducted in R statistical programming software version 3.5.3 (R Core Team, 2019). Missing data were not of significant concern. When examining missingness for the variables used in this analysis, I found at most $3(0.8 \%)$ missing data points for only seven of the overall survey questions used.

\section{Results}

\section{Assumptions of normality}

Skewness and kurtosis were examined; no single measure violated the univariate normality acceptable range values \pm 2.0 for skewness or values \pm 7.0 for kurtosis for data with a sample size greater than 300 (West et al., 1995). Mardia's test for multivariate normality found that our data was not multivariate normal. Micceri's (1989) work evaluating real-world psychometric distributions found that non-normality is common. However, given the multivariate normality test outcome, a SatorraBentler $\left(\mathrm{SBX}^{2}\right)$ mean adjusted test statistic was used to account for non-normality in the distributions (Satorra \& Bentler, 2010). Additionally, a robust maximum likelihood (MLM) estimator was used. MLM corrects for both the model chi-square and the parameter estimates' standard errors for deviations from a normal distribution (Brown, 2015; Satorra \& Bentler, 2010).

\section{Measurement model}

The measurement model was evaluated using confirmatory factor analysis. The Satorra-Bentler adjusted chisquare test for goodness of fit was $\mathrm{SBX}^{2}=78.31, d f=55$, $p<.05$. A significant chi-square goodness of fit is expected as this test is sensitive to large sample sizes $(n>$ 200); this is a commonly reported index in SEM analysis (Brown, 2015; Kline, 2016; Lomax \& Schumacker, 2004). The fit indices suggest a good overall model fit, CFI of 0.99 , TLI of 0.99 , RMSEA of 0.040 with a $90 \%$ confidence interval of $[0.016,0.059]$, and SRMR of 0.025 . Overall, the fit indexes suggest a good model fit.

All standardized factor loadings were above 0.80 , above the recommended 0.45 minimum (Tabachnick \& Fidell, 2013). Indicator reliabilities, evaluated by individually squaring the standardized factor loadings, were above 0.50 , demonstrating that each item measured above 50 percent of the true-score variance (Brown, 2015). The amount of variance captured by each latent construct was greater in relation to the amount of variance due to measurement error, i.e., variance was above 0.50 (Fornell \& Larcker, 1981). The reliability of the constructs, evaluated using Cronbach's alpha, were between 0.89 and 0.91 , which are considered above the recommended alpha value of 0.70 , indicating good construct reliability (Tavakol \& Dennick, 2011). Details of the confirmatory factor analysis estimates and fit indices can be found in Table 2 and the correlated coefficients for all constructs and single indicators can be found in Table 3 .

\section{Measurement invariance}

A measurement invariance test was conducted to determine if minoritized and majoritized women conceptualized the items and latent constructs from the belongingness and engineering identity scale similarly. Four models for measurement invariance were tested, configural, metric, scalar, and strict invariance, using a chi-square difference test, summarized in Table 4. Testing for measurement invariance is a multi-step process where each model is tested against the more increasingly restrictive model. A scaled chi-square difference test was used to determine which model fits the data better and determine if a parameter needs to be freely estimated. This paper will not provide a comprehensive discussion of measurement invariance; however, a thorough examination can be found in Brown (2015), Kline (2016), and Sass and Schmitt (2013). Additionally, two examples of measurement invariance with undergraduate engineering students can be found in prior published work (Verdín, Godwin, et al., 2019; Verdín \& Godwin, 2017b).

Table 4 provides a summary of all the measurement invariance models tested. Model 1: configural invariance was tested against model 2: metric invariance, a nonsignificant change in chi-square supported metric invariance $\left(\Delta \chi^{2}(8)=8.19, p=.415\right)$. When testing for scalar invariance (model $3 \mathrm{a})$, the scaled chi-square test demonstrated a significant difference between model $3 \mathrm{a}$ and model $2\left(\Delta \mathrm{X}^{2}(8)=28.54, p<.001\right)$ indicating a variation between the less restricted model to the more restricted model. The intercepts of the observed measures were examined to identify which yields the highest expected parameter change. One intercept was freely estimated across groups (i.e., "I feel I belong in engineering"). Scalar invariance with one parameter freely estimated (model 3b), was tested against the less restricted metric invariance model 2 , no significant difference between the two models was found $\left(\Delta \chi^{2}(7)=12.36, p=.089\right)$, thus establishing partial scalar invariance. Strict invariance (model 4) was tested against the partial scalar invariance (model 3b), the chi-square difference tests indicated no significant difference between the two models $\left(\Delta \chi^{2}(13)=9.82, p=.709\right)$. Since one parameter needed to be freely estimated, i.e., model $3 \mathrm{~b}$, the author can only claim partial measurement invariance and comparison testing across groups should not include the freely estimated variable.

\section{Structural invariance}

After establishing partial measurement invariance, the next step in invariance testing is to examine the structural paths (i.e., structural invariance). However, for this 
Table 2 Summary of measurement model estimates and factor reliabilities for all women

\begin{tabular}{|c|c|c|c|c|c|}
\hline Observed variables & Std. factor loadings & $S E$ & Item reliability & Construct reliability & Average variance extracted \\
\hline Interest & & & & .89 & .74 \\
\hline $\begin{array}{l}\text { I am interested in learning more about } \\
\text { engineering. }\end{array}$ & .83 & .06 & .63 & & \\
\hline I enjoy learning engineering. & .92 & .06 & .84 & & \\
\hline I find fulfillment in doing engineering. & .84 & .08 & .71 & & \\
\hline Recognition & & & & .88 & .78 \\
\hline My instructors see me as an engineer. & .91 & .07 & .83 & & \\
\hline My peers see me as an engineer. & .86 & .07 & .73 & & \\
\hline Performance/Competence & & & & .87 & .70 \\
\hline $\begin{array}{l}\text { I am confident that I can understand } \\
\text { engineering in class. }\end{array}$ & .88 & .07 & .78 & & \\
\hline $\begin{array}{l}\text { I am confident that I can understand } \\
\text { engineering outside of class. }\end{array}$ & .80 & .07 & .64 & & \\
\hline I can do well on exams in engineering. & .81 & .06 & .66 & & \\
\hline Belonging in the Major & & & & .89 & .81 \\
\hline I feel comfortable in engineering. & .90 & .06 & .81 & & \\
\hline I feel I belong in engineering & .90 & .06 & .81 & & \\
\hline Belonging in the classroom & & & & .89 & .73 \\
\hline I feel comfortable in my engineering class. & .86 & .07 & .73 & & \\
\hline I feel supported in my engineering class. & .84 & .07 & .71 & & \\
\hline I feel that I am part of my engineering class. & .86 & .06 & .74 & & \\
\hline
\end{tabular}

All standardized factor loadings are significant at $p<.001$, acceptable values of item reliability $>.50$, construct reliability $>.70$, and average variance extracted $>.50$

study, the structural paths were not constrained to be equal across groups as the purpose was to understand how minoritized women and majority women's engineering identity and sense of belonging differentially supported their commitment towards graduating with an engineering degree. The final model resulted in unique structural relationships across groups.

\section{Overall structural model fit}

The final structural model fit yield a Satorra-Bentler adjusted chi-square test for goodness of fit was $\mathrm{SBX}^{2}=$ 204.74, $d f=602, p<.010$. The fit indexes were CFI of 0.985 , TLI of 0.905 , RMSEA of 0.039 with a $90 \%$ confidence interval of [0.023, 0.052], and SRMR of 0.041. An illustration of the model can be found in Fig. 1; a discussion of the significant paths for minoritized and majority women follows.

\section{Estimates of structural model: minoritized women}

Minoritized women's beliefs about performing well in their courses and understanding content material helped to sustained their interest in engineering and promoted external recognition $(\beta=0.72, p<.000 ; \beta=0.53, p<$ .001 , respectively). In this study, external recognition is conceptualized as others' views of the student as an engineer (e.g., My instructors see me as an engineer).

Table 3 Correlation coefficients of latent constructs and single indicators

\begin{tabular}{llllll}
\hline & $\mathbf{1}$ & $\mathbf{2}$ & $\mathbf{3}$ & $\mathbf{4}$ & $\mathbf{5}$ \\
\hline 1. Engineering Interest & & & & & \\
2. Engineering Recognition & .54 & & & & \\
3. Engineering Performance/Competence beliefs & .71 & .57 & & & \\
4. Belong in the Engineering Major & .58 & .63 & .66 & .84 & .64 \\
5. Belong in the Engineering Classroom & .53 & .62 & .68 & .48 \\
6. I see myself as an engineer & .71 & .64 & .54 & .64 & .50 \\
7.I feel certain about graduating with an engineering degree & .63 & .43 & .57 & .54 \\
\hline
\end{tabular}


Table 4 Summary of testing measurement invariance between minoritized women and majoritized women

\begin{tabular}{|c|c|c|c|c|c|c|c|c|}
\hline Fit Index & Model & $X_{S B}^{2}(d f)$ & CFI & $\begin{array}{l}\text { RMSEA }(90 \% \\
\text { CI) }\end{array}$ & $\begin{array}{l}\Delta X^{2} s B \\
(\Delta d f)\end{array}$ & $\Delta P$ & $\Delta \mathrm{CFI}$ & $\triangle \mathrm{RMSEA}$ \\
\hline Model 1: Configural invariance (factor structure) & - & $\begin{array}{l}155.84 \\
(110)\end{array}$ & .980 & $\begin{array}{l}.055 \\
(.031-.061)\end{array}$ & - & - & - & - \\
\hline Model 2: Metric Invariance (factor structure + loadings) & $\begin{array}{l}\text { M2 vs. } \\
\text { M1 }\end{array}$ & $\begin{array}{l}163.46 \\
(118)\end{array}$ & .980 & $\begin{array}{l}.045 \\
(.030-.059)\end{array}$ & $8.19(8)$ & .415 & .000 & .010 \\
\hline $\begin{array}{l}\text { Model 3a: Scalar invariance (factor structure + loadings + } \\
\text { intercepts) }\end{array}$ & $\begin{array}{l}\text { M3a vs. } \\
\text { M2 }\end{array}$ & $\begin{array}{l}184.03 \\
(126)\end{array}$ & .975 & $\begin{array}{l}.050 \\
(.035-.063)\end{array}$ & $28.54(8)$ & .000 & .005 & .005 \\
\hline $\begin{array}{l}\text { Model 3b: Partial scalar invariance (factor structure + loadings + } \\
\text { intercepts) }\end{array}$ & $\begin{array}{l}\text { M3b vs. } \\
M 2\end{array}$ & $\begin{array}{l}174.82 \\
(125)\end{array}$ & .978 & $\begin{array}{l}.046 \\
(.031-.060)\end{array}$ & $12.36(7)$ & .089 & .003 & .004 \\
\hline $\begin{array}{l}\text { Model 4: Strict invariance (factor structure + loadings }+ \text { intercepts } \\
+ \text { error variances) }\end{array}$ & $\begin{array}{l}\text { M4 vs. } \\
\text { M3b }\end{array}$ & $\begin{array}{l}180.56 \\
(138)\end{array}$ & 0.981 & $\begin{array}{l}.041 \\
(.025-.054)\end{array}$ & $9.82(13)$ & .709 & .002 & .006 \\
\hline
\end{tabular}

Performance/competence beliefs helped explain 52\% of the variance for minoritized women's interest in engineering, while only explaining $28 \%$ of the variance for the external recognition construct. Interest and external recognition were almost equally important for minoritized women's beliefs of seeing themselves as engineers $(\beta=$ $0.44, p<.001 ; \beta=0.48, p<.001$, respectively). There was no direct effect between performance/competence beliefs onto minoritized women's perceptions of seeing themselves as engineers. Rather, interest in engineering and recognition by others mediated the effect between performance/competence beliefs and students' perceptions of seeing themselves as engineers. Interest in engineering and receiving recognition as someone that can do engineering helped explain $58 \%$ of the variance for the single indicator, I see myself as an engineer. Minoritized women's sense of belonging in the major and in the classroom environment was supported through their confidence in their ability to perform well and understand engineering course content (i.e., performance/ competence beliefs; $\beta=0.24, p<.05$ and $\beta=0.39, p<$ .001 , respectively) and through recognition from their instructors and peers $(\beta=0.49, p<.001$ and $\beta=0.43, p$ $<.001$, respectively). Notably, receiving external recognition from instructors and peers was twice as important for minoritized women's sense of belonging in the major compared to having confidence in their performance abilities and recognizing themselves as engineers (i.e., $I$ see myself as an engineer). Belonging in the major and in the classroom were highly correlated $(r=0.65, p<.001)$;

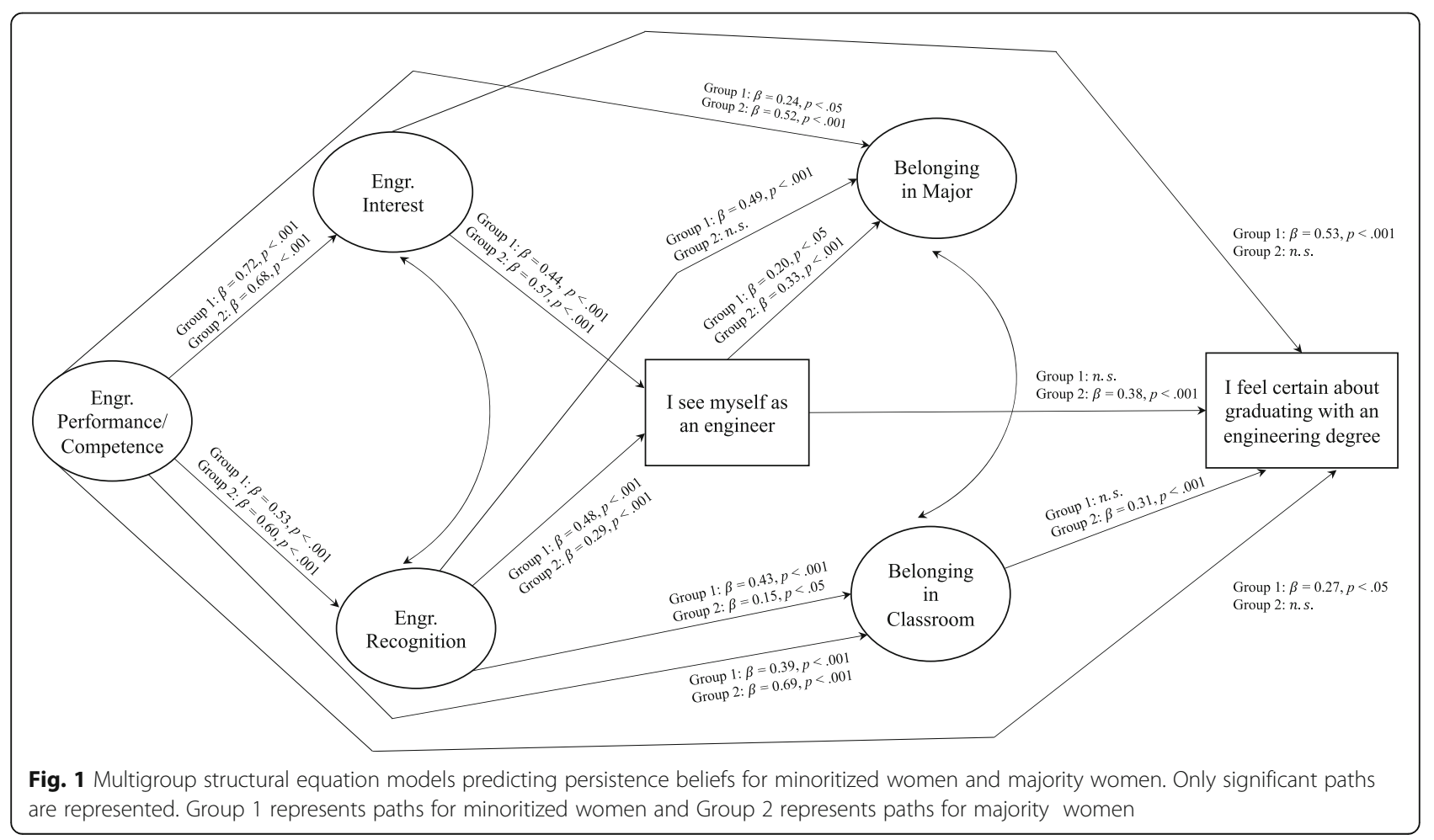


yet, there were both distinctions and commonalities between the factors that promoted belongingness in the major and in the classroom. Seeing oneself as an engineer supported sense of belonging in the major $(\beta=0.20$, $p<.05)$, but not the classroom setting. Additionally, feeling a sense of belonging both in the major and in the classroom was not predictive of minoritized women's certainty to graduate with an engineering degree. Minoritized women's performance/competence beliefs and receiving external recognition helped explained $48 \%$ of the variance for the construct of belonging in the classroom. While performance/competence beliefs, internal and external recognition helped explained $65 \%$ of the variance for the construct of belonging in the engineering major.

Minoritized women's perceptions of themselves as engineers (i.e., I see myself as an engineer) did not support their beliefs about persisting towards degree completion. Remarkably, certainty of persisting towards degree completion was largely supported by minoritized women's developed interest in engineering $(\beta=0.53, p<.001)$ and through an established confidence in their abilities $(\beta=0.27, p<.05)$. The two identity shaping constructs, i.e., interest and performance/competence beliefs, explained $55 \%$ of the variance of minoritized women's persistence beliefs. More so, interest was two times more predictive of their certainty of graduating with an engineering degree compared to having confidence in their abilities. Lastly, the two modes of belonging did not significantly support minoritized women's belief about persisting toward degree completion.

\section{Estimates of structural model: majority women}

Interest in engineering and recognition by others mediated the effect between performance/competence believes and internal recognition. No significant direct effect between performance/competence beliefs onto majority women's beliefs of seeing themselves as engineers was found. There was a small and significant correlation between interest and recognition that was not present in the model of minoritized women $(r=0.20, p$ $<.01)$. Majority women's interest in engineering and receiving external recognition supported their selfidentification as engineers $(\beta=0.57, p<.001 ; \beta=0.29, p$ $<.001$, respectively). Being interested in engineering was twice as important toward majority women's perceptions of seeing themselves as engineers compared to receiving external recognition. The constructs of interest and recognition explained $61 \%$ of the variance for the single indicator, I see myself as an engineer. A sense of belonging in the major was supported through majority women's beliefs in their ability to perform well and understand engineering content (i.e., performance/competence beliefs, $\beta=0.52, p<.001)$, as well as their identification as an engineer $(\beta=0.33, p<.001)$; which explained $57 \%$ of the variance. Majority women's beliefs in their performance capabilities and receiving external recognition supported their sense of belonging in the classroom $(\beta=$ $0.69, p<.001 ; \beta=0.15, p<.05$, respectively). Believing one can perform well and understand the content being taught was four times more influential on majority women's sense of belonging in the classroom. Together, confidence in one's ability and receiving external recognition explain $62 \%$ of the variance for majority women's sense of belonging in the classroom. Lastly, majority women's beliefs about persisting to degree completion was supported by their sense of belonging in the classroom $(\beta=0.31, p<.001)$ and views of themselves as engineers $(\beta=0.38, p<.001)$, explaining $35 \%$ of the variance. While belonging in the classroom and belonging in the major were found to be highly correlated $(r=$ $0.72, p<.001$ ), belonging in the engineering major did not directly support persistence beliefs; nevertheless, the strong correlational relationship with classroom belonging may indirectly support persistence toward graduating.

\section{Discussion}

The purpose of this study was to understand how an engineering identity and feeling a sense of belonging promoted women's persistence beliefs. I also sought to understand how the facets of engineering identity and belongingness differentially supported minoritized women and majority women's persistence beliefs. In the structural equation model, equality constraints were not placed on the structural paths to allow for relationships to be unique for each group. A discussion of the similarities and differences across groups related to developing an engineering identity are discussed first. Following, I examine the differential influence between the engineering identity constructs and modes of belonging. Lastly, I discuss the differential influence the engineering identity shaping constructs and modes of belonging have on women's certainty of graduating with an engineering degree (i.e., persistence beliefs).

\section{Mediational relationship between the engineering identity constructs}

The model shows a mediating relationship of interest and recognition between performance/competence beliefs and identification as an engineer for minoritized and majority women. The mediational effect expands prior findings by focusing on a student population that was not previously examined (e.g., Godwin \& Kirn, 2020; Godwin et al., 2016; Verdín, Smith, \& Lucena, 2019; Verdín, Godwin, Kirn, et al., 2018). Carlone and Johnson (2007) affirm that disciplinary identities are based on students' performance practices and their display of competence triggers recognition as a STEM type of 
person from individuals situated in their immediate environment. The relationship discussed by Carlone and Johnson (2007) is further evidenced in the mediational relationship and the lack of direct effect between performance/competence beliefs and students' perceptions of seeing themselves as engineers. Godwin \& Kirn (2020) and Verdín, Godwin, Kirn, et al. (2018) modeled relationships whose results emphasized that receiving external recognition was the most influential factor toward identity development; however, the present model contradicts those findings. Prior studies (i.e., Godwin \& Kirn, 2020; Verdín, Godwin, Kirn, et al., 2018) conducted a structural equation modeling analysis with samples that were overrepresented of men, and men are more likely to be perceived as engineers (e.g., Jorgenson, 2002; Tonso, 1996, 1999, 2007), perhaps explaining the overemphasis on being externally recognized. In this study, women's interest in engineering was as important to their perception of seeing themselves as engineers, while the effect was slightly greater for majority women.

Additionally, there was a significant correlation between engineering interest and being externally recognized as an engineer for majority women. While for minoritized women, no correlation was found between engineering interest and external recognition. The absence of a correlation for minoritized women can imply that interest is not developed or sustained through others' validation (i.e., instructors or peers). Perhaps majority women are more likely to be afforded recognition in part because there is a greater representation of White and Asian/Asian American students and instructors in engineering; thus, the consistent messages of being seen as an engineer reinforces their interest. Whereas minoritized women are often more likely to be denied recognition (e.g., Carlone \& Johnson, 2007), more likely to experience prejudice or stereotype (e.g., Ong et al., 2011; Seymour \& Hewitt, 1997), or have their abilities and potential overlooked (Neal-Jackson, 2018; Tonso, 2007). To further examine the claim that majoritized women are more often recognized, I performed a post hoc analysis comparing minoritized and majority women's composite responses to the recognition variables. The results indicate that majority women were more likely to report being recognized by peers and instructors compared to minoritized women (majority women $\mathrm{M}=4.32, S E=.08$ and minoritized women $\mathrm{M}=$ $3.78, S E=.14$, adj. $p<.01$, respectively) with a Cohen's $d$ value of 0.23 . Placing too much emphasis on obtaining validation from others can systematically disenfranchise minoritized women's development of an engineering identity. Receiving recognition as an engineer is a response from the environment that validates the behavioral practices and attitudes in which students engage. However, students are not entirely free to develop any type of engineering identity, rather they are guided by "larger and more pervasive meanings of [engineering] identity derived from sociohistorical legacies of [engineering]; and historical and political meanings of being" a minoritized student (Carlone \& Johnson, 2007, p. 1192).

\section{Relationship between engineering identity and modes of belonging}

Tonso (2007) posited that "identities serve as focal points for learning to belong in communities of practice" (p. 27). Other scholars have also affirmed that identity development and a sense of belonging are intimately related (Meyers et al., 2012; Osterman, 2000). Osterman (2000) affirmed that when students experience a sense of belonging, they are more likely to "establish a stronger sense of identity" (p. 331), suggesting that belonging is a precursor for identity development. Hazari et al. (2020), who used similar identity constructs in the physics context, found that for women physicists in their senior year (i.e., fourth-year or greater), a sense of belonging supported their belief of seeing themselves as a physics person. In light of these studies, both relationships were tested, that is, modes of belonging supporting identity and identity supporting modes of belonging. I found no significant relationship between the two modes of belonging onto women's beliefs of seeing themselves as engineers (i.e., belonging $\rightarrow$ engineering identity), further supporting Tonso's (2007) theoretical claim that the development of a disciplinary identity supports belongingness in the discipline (i.e., engineering identity $\rightarrow$ belonging). Additionally, for both groups of women, seeing oneself as an engineer supported their sense of belonging in the major but not the classroom environment.

Receiving external recognition from instructors or peers was the most important factor for minoritized women's sense of belonging both in the major and in the classroom. Whereas for majority women, receiving external recognition only moderately supported their classroom belongingness. This study demonstrates that minoritized women's sense of belonging is largely contingent on external factors (i.e., receiving recognition by others). Perhaps because belongingness connotes acceptance, fit, and inclusion (Museus et al., 2017) and these forms of belonging are reproduced by the environment or disciplinary culture (Hurtado \& Carter, 1997; Maestas et al., 2007). The interaction students' have with their peers and engineering instructors could be a doubleedged sword, an opportunity to reinforce positive beliefs about oneself or a mentally taxing experience that requires negotiation strategies. It is worrisome that minoritized women are reporting lower levels of recognition as engineers from their instructors and peers than majority women, evidenced in the post hoc analysis, especially since external recognition is most important for their 
sense of belonging in the major and classroom environment. Rainey and colleagues (2021) identified strategies engineering faculty can implement to support minoritized women's sense of belonging in the classroom. Strategies that specifically support minoritized women include 1) creating an atmosphere that invites clarifying questions that do not call into question women's belongingness when they do not understand course-related material. 2) posting a flexible and more available office hours schedule, and 3) when instructors foster an atmosphere of mutual respect (Rainey, Verdín, \& Smith, 2021). Fostering an atmosphere of mutual respect in an engineering classroom could be understood as recognizing the different lived experiences of minoritized women and moving past the hegemonic masculine culture. Often lived experiences celebrated in the classroom are those stereotypical to men; thus, engineering educators must reflect on the narrative they portray in their classroom environments to avoid further marginalizing women's experiences. For both groups of women, performance/competence beliefs support their belongingness in the engineering classroom and major. Pajares (1996) affirmed that self-evaluations of one's capabilities to perform well on a given domain task (akin to performance/competence beliefs) also influence the individuals' thought patterns and emotional reactions. In the model of majority women, their performance/competence beliefs were four times more influential towards their sense of belonging in the classroom compared to the external recognition construct. For minoritized women, their performance/competence beliefs and external recognition almost equally supported their sense of belonging in the classroom. This finding also offers a strategy engineering educators can employ to promote belongingness in their classroom, i.e., recognized women's performance capabilities. These findings offer a strategy engineering educators can employ to promote belongingness in their classroom, i.e., recognized women's performance capabilities. An ideal approach to support women's modes of belonging is to emphasize a growth mindset both in the classroom environment and as a general trait engineers should embrace. A growth mindset invites students to think about their capabilities as attainable through continuous effort as opposed to innate or naturally bestowed. Conveying to students that their capability to learn engineering concepts is a gradual progression may help promote belongingness.

\section{Certainty of graduating with an engineering degree}

In the model of minoritized women, interest in engineering had the largest effect on their persistence beliefs. Notably, the relationship between interest in engineering and certainty of graduating was more pronounced for minoritized women. The latent variable of engineering interest can be understood through Hidi and Renninger's (2006) characterization of well-developed individual interest, i.e., an individuals' "relatively enduring predisposition to reengage with particular classes of content over time" (p. 115). The majority of the students sampled for this study were enrolled as third year or higher (67\%), which could explain their well-developed interest in the field. Scholars who study interest also acknowledge that interest is a motivational predisposition to engage and reengage with content over time (Renninger \& Su, 2012; Renninger, 2009). Specifically, learners who are interested in specific tasks "are likely to be able to selfregulate and persist to complete tasks even when they are challenged, whereas learners with little interest typically have difficulty engaging and continuing to work with tasks" (Renninger et al., 2015, p. 2). In a study of engineering students, Patrick et al. (2018) affirmed that students' sustained interest in engineering supported their persistence, measured by tracking enrollment over twotime points. Further drawing attention to the importance of continuously strengthening and sustaining student's interest in engineering.

Additionally, the identity shaping construct of performance/competence beliefs contributed toward minoritized women's persistence beliefs both directly and indirectly, i.e., through its influence on interest. Performance/competence beliefs are perceptions of one's confidence in understanding course content and performing well on engineering-related tasks, e.g., exams. The importance of further reinforcing minoritized women's performance/competence beliefs should not be overlooked as reinforced confidence can further engender interest in engineering. Performance/competence beliefs are conceptually analogous to Bandura's self-efficacy beliefs. Bandura (1997) argues that self-efficacy beliefs at an early age are task-specific and as individuals mature, overtime, self-efficacy beliefs become more generalized in a given domain. The relationship between students' self-efficacy beliefs and academic persistence has had mixed results, with some studies demonstrating significant relationships (e.g., Bettencourt et al., 2020; Brown et al., 2008; Hackett et al., 1992; Lent et al., 1986; Multon et al., 1991; Verdín et al., 2020) and other studies demonstrating no significant relationships, direct or indirect (e.g., Lee et al., 2015; Patrick et al., 2018). Interestingly, in the present study, beliefs about one's ability to understand engineering content material and its relationship with persistence beliefs were contingent on group membership. Specifically, performance/competence beliefs were important for minoritized women both directly and indirectly, yet only indirectly supported majority women's beliefs about persisting.

Seeing oneself as an engineer and being interested in engineering supported majority women's certainty of 
graduating. Identifying as an engineer goes beyond the acquisition of knowledge, skills, and disciplinary practices; it also involves understanding oneself in relation to a discipline (Stevens et al., 2008). Oyserman (2015) describes that an individuals' identity serves to guide behavior that is congruent with their established identity. The behaviors that people engage in through their new roles or interactions are "critical elements in helping individuals define themselves as occupants of a particular position" (Burke et al., 2003, p. 42). When a student experiences difficulty in a task (e.g., an engineering course assignment, exam, etc.), Oyserman (2015) declares that the experienced difficulty will reinforce their identitycongruent interpretation, that is, the individual will assign importance to achieving the difficult task in order to maintain congruence. In the present study, majority women's identification as engineers supported their persistence toward graduation, thus the difficulties they may experience throughout their trajectory may not deter their efforts as long as they continue to see themselves as engineers. Put simply, individuals become motivated to work toward images of themselves they see as attainable and aligned with who they want to become (Oyserman \& James, 2011). Research studies have concluded that identity development supports students' future commitment to the engineering field and students who were further along in their engineering degrees demonstrate more solidified engineering identities (e.g., Jones et al., 2013; Meyers et al., 2012; Pierrakos et al., 2009; Stevens et al., 2008; Tonso, 2006b). More than half of the sample of women, from both groups, reported being enrolled in college for three or more years (see Table 1), thus I conjecture that having longer exposure to the discipline may have helped solidify their engineering identity. However, having a more solidified engineering identity only supported majority women's persistence beliefs but not women in the minoritized group, partially supporting the claim made by other scholars. Perhaps the in-group representation afforded to majority women allows them to see themselves as engineers. However, it is also important to acknowledge that women in general experience recurring instances of marginalization in engineering due to a lack of "fit" between the prototypical masculine stereotype of an engineer and their views of themselves as engineers (e.g., Benedict, Verdín, Baker, Godwin, \& Thielmeyer, 2018; Secules et al., 2018; Verdín, 2021). Notably, the longitudinal narrative analyses of Secules et al. (2018), who followed the experience of Emilia, an Asian American engineering student, and Verdín (2021), who followed the experience of Kitatoi, a Latina first-generation college student in engineering, as they retold episodes of marginalization that affected their sense of belonging in engineering. Based on the grouping distinctions in the present study, both women would belong to separate groups, i.e., minoritized women and majority women. While their race/ethnicity representation in engineering differs starkly, the experience of being a woman in a male-dominated field was similar. In both studies, the women progressed toward degree completion by handling issues of belongingness differently. Thus, the present study adds an additional layer of understanding to include the mechanisms that promote persistence beliefs for women from racial/ethnic groups that are differentially represented in engineering.

A salient distinction between minoritized and majority women was the relationship between belonging in the classroom onto their certainty of graduating with an engineering degree. For minoritized women, modes of belonging did not support their certainty to persists, while majoritized women's classroom belongingness positively supported their certainty of persisting. The relationship between classroom belonging onto certainty to persists highlights a key distinction between women who are perceived to be outside the margins of engineering and women who are considered in-group members due to higher representation of their race/ethnicity in the field. Revisiting Inez's story, Inez's experience was a powerful account of what many racial/ethnically diverse students face in engineering. Inez's advice to engineering educators was "try to make people feel more welcome. That may be hard, but I never felt like I was welcome[d]" (Foor et al., 2007, p. 113). In the classroom environment, Inez's knowledge and competence was questioned by instructors and she observed her instructors play favoritism with students who have had certain experiences that were not attainable to her, "being 'a co-op' puts one in elite company at this institution ..." (Foor et al., 2007, p. 110). I further investigated the possible distinction between belonging in the classroom based on women's group membership. Findings from a post-hoc Welch's $t$ test, further supports the claim that minoritized women are less likely to feel as though they belong in the major (measured using the item "I feel comfortable in engineering") and less likely to feel they belong in the classroom environment compared to majoritywomen (belonging in the major: $\mathrm{M}=4.28, S E=.08$ and $\mathrm{M}=$ 3.93, $S E=.13$, adj. $p<.01)$ with a Cohen's $d$ value of 0.22 and (belonging in the classroom: $\mathrm{M}=4.25, S E=.08$ and $\mathrm{M}=3.52, S E=.14$, adj. $p<.001)$ with a Cohen's $d$ value of 0.31 .

The results of the model for minoritized women and Inez's experience seem to contradict longstanding beliefs that belongingness supports persistence (e.g., Marra et al., 2012; Rainey et al., 2018; Seymour \& Hewitt, 1997; Seymour \& Hunter, 2019; Strayhorn, 2018). A possible explanation could be that minoritized women whose lack of belonging affected 
their persistence may have already left the field; thus, belongingness can explain why some minoritized women leave but is an incomplete explanation of why others persist. Holland (2019) studied the effect of belonging on students' intentions to persist or switch STEM fields found that "the main difference between switchers and persisters was how belonging issues were handled" (p. 318 emphasis in original). The experience of Inez is a noteworthy example of how issues of belongingness can be deflected by focusing on other affective states. While not explicitly stated in the Foor et al. article, I believe that Inez was able to successfully navigate engineering, despite many challenges and lack of belonging, because she was able to see herself in the role of being an engineer and positioned herself accordingly, even though she never felt as if she belonged. Inez's perseverance despite feeling unwelcomed in her engineering classes and the department is perhaps a result of having sustained interest in engineering. For example, Inez had instances where her interest in the field was sustained, she spoke about being able to solve a design problem for her boyfriend's family home and she remained interested in engineering despite not receiving good grades,

everyone said switch majors if I am not doing good ... I didn't want to leave engineering to get better grades ... I wanted to enjoy what I was doing. And I knew engineering was what I wanted to do (Foor et al., 2007, p. 107).

Similar to Inez, in the model of minoritized women, a well-developed interest in engineering supported persistence. It could be concluded that when minoritized women's well-developed interest in engineering begins to frail, then, perhaps, their lack of belongingness could be a contributing factor toward their decision to leave the field.

\section{Implications}

The results of this study provide educators with a nuanced understanding of how identity development and modes of belonging differentially affect women's persistence beliefs. Seeing oneself as an engineer is not simply a matter of self-selection; it is a process that involves being confident in one's ability to do well in engineering, having a developed and sustained interest in engineering, and receiving external recognition by members of the engineering community. Each aspect of this process is important toward ultimately seeing oneself as an engineer. However, as the model has demonstrated, some components that support identity development are more important toward establishing a sense of belonging and supporting persistence. Scholars have long argued the importance of identifying with a discipline (e.g., Carlone \& Johnson, 2007; Cribbs et al., 2015, 2016; Hazari et al., 2010; Stevens et al., 2008; Tonso, 2006a; Verdín, Godwin, \& Ross, 2018); yet, equally important are the individual components that support students' identification with a discipline and the differential effects these components have on persistence based on women's social position. It is imperative that educators understand the powerful influence minoritized women's interest in engineering has on their persistence beliefs and create mechanisms to continuously sustain their interest. Renninger (2009) cautions scholars that interest needs to be sustained and continuously cultivated irrespective of the phase of interest development (i.e., phase 1: triggered situational interest versus phase 4: well-developed individual interest). Interest is both an affective and cognitive state, thus providing educators multiple ways to support minoritized women's interest in engineering. Educators can be intentional in nourishing students' interest in engineering by focusing on both the student's enjoyment of the topics being taught and the intellectual stimulation that accompanies learning and discovery. Studies have found that women are more inclined to choose career fields that support their altruistic disposition (e.g., Carlone \& Johnson, 2007; Espinosa, 2011; Seymour \& Hewitt, 1997; Seymour \& Hunter, 2019); more so, Carlone and Johnson (2007) found that minoritized women in their study maintained their interest despite receiving discouragement from their environment because interest was rooted in altruistic intentions. I encourage engineering educators to focus design activities on tasks that situate student engineers in a context that makes space for altruism to be leveraged. Educators should spend more time helping minoritized women maintain their interest in the discipline by implementing open-ended activities that allow for specific interests to be further explored and celebrated in the classroom setting.

Lastly, while modes of belonging did not support minoritized women's certainty of graduating with an engineering degree, educators should not conclude that establishing a sense of belonging is not important. In fact, the post-hoc results demonstrated that minoritized women were less likely to feel a sense of belonging in the major and classroom environment. I invite engineering educators to critically reflect on the practices and conversations taking place in their engineering classrooms. For example, could educators be inadvertently sending minoritized women a message that engineers are only White and male by showing images of White male engineers or providing examples of success from White male engineers? The narrative account of a Latina, first-generation college student in Verdín (2021) 
provides a powerful account of how educators' socializing messages of who fits and belongs in engineering can damage a student's self-concept. Additionally, Museus et al. (2017) documented that students' sense of belonging was supported through four culturally engaging elements, (1) when students felt that "their cultural knowledge, backgrounds, and identities were valued"; (2) students' ability to connect with faculty members, staff, or peers with similar backgrounds and experiences; (3) when institutional agents made information about opportunities and support resources more visible to students; and (4) establishing trust with one faculty or staff member (p. 192). Scholars have drawn awareness to the disconnect between engineering courses and students' ability to connect and leverage their household and cultural knowledge systems to their learning (Smith \& Lucena, 2016; Verdín, Smith, \& Lucena, 2019; Verdín et al., 2020). Thus, finding ways to incorporate students' household and cultural knowledge systems into engineering may provide an opportunity for minoritized women to develop a sense of belonging.

\section{Limitations and future work}

This study provides an understanding of how identity and belongingness promote persistence beliefs differently based on students' position in the engineering culture (i.e., being from a minoritized versus a majority group); yet, it does not come without limitations. First, data were collected at one point in time; therefore, it does not capture the dynamic and malleable nature of identity development. One's sense of belonging and identification as an engineer can fluctuate based on lived experiences both in and out of the classroom environment. A more holistic understanding of identity development and belongingness could be achieved through multiple rounds of data collection over time. Future work will examine how minoritized women's belongingness and engineering identity develop over time and how these constructs inform their persistence beliefs. Second, single-item measures are often viewed skeptically. There are disadvantages associated with using a single-item measure, including the inability to calculate an internal reliability score, vulnerable to unknown bias in interpretation, and could be subject to measurement error (Hoeppner et al., 2011). Despite known drawbacks, there are several studies using various survey scales that found a single-item measure performed sufficient or comparable to multi-item measures (e.g., Bergkvist \& Rossiter, 2007; Drolet \& Morrison, 2001; Gardner et al., 1998; Hoeppner et al., 2011).

I acknowledge that students experience the culture of engineering differently depending on their backgrounds. Grouping together minoritized and majority women provides a layer of understanding of how they experience the engineering culture; however, further parsing out groups into their respective race/ethnic categories would provide even richer insights. I could not further disaggregate the data by students' specific race/ ethnic groups as structural equation modeling requires large sample sizes per group. Additionally, all women experience the culture of engineering differently due to the masculine social norms built into the fabric of the profession. For example, the work of Secules et al. (2018) examines the experiences of marginalization in engineering for an Asian American student. While his study did not focus on belongingness or identity development, it is one example of how marginalization in engineering is experienced by students in intersecting groups (i.e., membership in gender minority and racial majority groups). Future work will examine how women across racial/ethnic groups establish a sense of belonging and develop their identities as engineers. Lastly, these results are situated in the US context thus the relationship between identity development, belongingness, and persistence beliefs may differ for students in regions outside the contiguous US states and internationally. Future work should examine if the relationships established in the present study hold true for women in intersectional racialized/minoritized groups outside the US context. To examine if the connections established in this study are reliable outside the US context, researchers should first determine if the measures for engineering identity and modes of belonging apply to their student population through psychometric testing.

\section{Conclusion}

Scholars have long claimed that developing an engineering identity and establishing a sense of belonging supports students' commitment and persistence toward graduating in a STEM field. However, some women persist in engineering and, broadly, STEM, despite having a disrupted sense of belonging; the story of Inez exemplifies this phenomenon. While women in the USA makeup only $22 \%$ of undergraduate engineering degree recipients and can experience an unwelcoming engineering culture based on their gender, there are advantages afforded to women who are non-stigmatized or majority group members. White and Asian/Asian American women have the advantage of being viewed as in-group members due to their broader engineering representation. This study demonstrates that identifying as an engineer and establishing a sense of belonging in the classroom supports majority women's persistence toward graduating with an engineering degree. While minoritized women in engineering face the double-bind dilemma where the engineering culture marginalizes them for being women and members of a racialized group. The model of minoritized women demonstrated that 
belonging in the major and classroom did not support their certainty to persist towards degree completion.

Additionally, seeing oneself as an engineer did not promote minoritized women's persistence; instead, persistence was supported by the constructs that encourage identity development, i.e., performance/competence beliefs and interest. However, interest in engineering demonstrated a greater disposition toward encouraging persistence. The affective and cognitive state of being interested in a domain or discipline should not be neglected; efforts should be made to continue bolstering minoritized women's interest in engineering.

\begin{abstract}
Abbreviations
Adj. $p$ : False discovery rate adjusted $p$ value; $\beta$ : Standardized coefficient; CFA: Confirmatory factor analysis; CFI: Comparative Fit Index; FDR: False discovery rate; M: Mean; SBX2: Satorra-Bentler adjusted chi-square test for goodness of fit; SE: Standardized error; SEM: Structural equation modeling; STEM: Science, Technology, Engineering, and Mathematics;

SRMR: Standardized root mean square residual; RMSEA: Root mean square error of approximation; TLI: Tucker-Lewis Index
\end{abstract}

\section{Acknowledgements}

The author wishes to thank Drs. Jessica M. Smith and Juan C. Lucena. Drs. Smith and Lucena were awarded the NSF EAGER Grant Number 1734044 that led to the data collected for this study.

\section{Author's contributions}

DV supported the data collection, solely conceived, designed, and conducted the analysis, and solely drafted the manuscript. The author(s) read and approved the final manuscript.

\section{Funding}

Funding for this work was provided by the National Science Foundation (NSF) EAGER Grant No. 1734044. Any opinions, findings, and conclusions or recommendations expressed in this material are those of the authors and do not necessarily reflect the views of the NSF.

\section{Availability of data and materials}

N/A

\section{Declarations}

\section{Competing interests}

The author declares no conflict of interest. The founding sponsors had no role in the design of the study; in the collection, analyses, or interpretation of data; in the writing of the manuscript; and in the decision to publish the results.

Received: 28 October 2020 Accepted: 21 April 2021

Published online: 07 May 2021

\section{References}

Ainley, M., Hidi, S., \& Berndorff, D. (2002). Interest, learning, and the psychological processes that mediate their relationship. Journal of Educational Psychology, 94(3), 545-561. https://doi.org/10.1037//0022-0663.94.3.545.

Bandura, A. (1989). Human agency in social cognitive theory. American Pscyhologist, 44(9), 1175-1184. https://doi.org/10.1037/0003-066X.44.9.1175. Bandura, A. (1997). Self-efficacy: The exercise of control. Worth Publishers.

Baumeister, R. F., \& Leary, M. R. (1995). The need to belong: Desire for interpersonal attachments as a fundamental human motivation. Psychological Bulletin, 117(3), 497-529. https://doi.org/10.1037/0033-2909.117.3.497.

Benedict, B., Verdín, D., Baker, R., Godwin, A., \& Thielmeyer, A. (2018). I don't flT the stereotype, but i see myself as an engineer: First-year engineering students' attitudes and beliefs about their engineering identities. In Proceedings - Frontiers in Education Conference, FIE. https://doi.org/10.1109/ FIE.2018.8659229
Benedict, B. S., Verdín, D., Baker, R. A., Godwin, A., \& Milton, T. (2018). Uncovering latent diversity: Steps towards understanding 'what counts' and 'who belongs' in engineering culture. In Paper presented at 2018 ASEE annual conference \& exposition, Salt Lake City, Utah. https://doi.org/10.18260/1-2 -31164 .

Benjamini, Y., \& Hochberg, Y. (1995). Controlling the false discovery rate: A practical and powerful approach to multiple testing. Journal of the Royal Statistical Society, 57(1), 289-300 https://www.jstor.org/stable/2346101.

Benjamini, Y., \& Yekutieli, D. (2001). The control of the false discovery rate in multiple testing under dependency. The Annals of Statistics, 29(4), 1165-1188 https://www.jstor.org/stable/2674075.

Bentler, P. M. (1990). Comparative fit indexes in structural models. Quantitative Methods in Psychology, 107(2), 238-246. https://doi.org/10.1037/0033-2909.1 07.2.238.

Bergkvist, L., \& Rossiter, J. R. (2007). The predictive validity of multiple-item versus single-item measures of the same constructs. Journal of Marketing Research, 44(2), 175-184. https://doi.org/10.1509/jmkr.44.2.175.

Bettencourt, G. M., Manly, C. A., Kimball, E., \& Wells, R. S. (2020). STEM degree completion and first-generation college students: A cumulative disadvantage approach to the outcomes gap. Review of Higher Education, 43(3), 753-779. https://doi.org/10.1353/rhe.2020.0006.

Betz, N. E., \& Hackett, G. (1986). Applications of self-efficacy theory to understanding career choice behavior. Journal of Social and Clinical Psychology, 4(3), 279-289. https://doi.org/10.1521/jscp.1986.4.3.279.

Beutel, A. M., \& Nelson, D. J. (2005). The gender and race-ethnicity of faculty in top social science research departments. Journal of Women and Minorities in Science and Engineering, 11(4), 389-402. https://doi.org/10.1007/3-540-33713-X_31.

Bix, A. S. (2004). From "engineeresses" to "girl engineers" to "good engineers": a history of women's U.S. engineering education. NWSA Journal, 16(1), 27-49. https://doi.org/10.1353/nwsa.2004.0028.

Boone, H., \& Kirn, A. (2016). First generation students identification with and feelings of belongingness in engineering. In Paper presented at 2016 ASEE annual conference \& exposition, New Orleans, Louisiana. https://doi.org/10.182 60/p.26903.

Brown, S. D., Tramayne, S., Hoxha, D., Telander, K., Fan, X., \& Lent, R. W. (2008). Social cognitive predictors of college students' academic performance and persistence: A meta-analytic path analysis. Journal of Vocational Behavior, 72(3), 298-308. https://doi.org/10.1016/j.jvb.2007.09.003.

Brown, T. A. (2015). Confirmatory factor analysis for applied research, (2nd ed., ). The Guilford Press.

Browne, M. W., \& Cudeck, R. (1993). Alternative ways of assessing model fit. In K. A. Bollen, \& J. S. Long (Eds.), Testing structural equation models, (pp. 136-162). Sage Publications.

Burke, P. J., Owens, T. J., Serpe, R. T., \& Thoits, P. A. (2003). Advances in identity theory and research. Springer. https://doi.org/10.1007/978-1-4419-9188-1.

Carlone, H., \& Johnson, A. (2007). Understanding the science experience of sucessful women of color: Science identity as an analytic lens. Journal of Research in Science Teaching, 44(8), 1187-1218. https://doi.org/10.1002/tea.20237.

Chase, M. M., Dowd, A. C., Pazich, L. B., \& Bensimon, E. M. (2014). Transfer equity for "minoritized" students: A critical policy analysis of seven states. Educational Policy, 28(5), 669-717. https://doi.org/10.1177/0895904812468227.

Chiu, M. M., Chow, B. W. Y., McBride, C., \& Mol, S. T. (2016). Students' sense of belonging at school in 41 countries: Cross-cultural variability. Journal of CrossCultural Psychology, 47(2), 175-196. https://doi.org/10.1177/0022022115617031.

Cribbs, J. D., Cass, C., Hazari, Z., Sadler, P. M., \& Sonnert, G. (2016). Mathematics identity and student persistence in engineering. International Journal of Engineering Education, 32(1), 163-171.

Cribbs, J. D., Hazari, Z., Sonnert, G., \& Sadler, P. M. (2015). Establishing an explanatory model for mathematics identity. Child Development, 86(4), 10481062. https://doi.org/10.1111/cdev.12363.

Drolet, A. L., \& Morrison, D. G. (2001). Do we really need multiple-item measures in service research? Journal of Service Research, 3(3), 196-204. https://doi. org/10.1177/109467050133001.

Espinosa, L. L. (2011). Pipelines and pathways: Women of color in undergraduate stem majors and the college experiences that contribute to persistence. Harvard Educational Review, 81(2), 209-240. https://doi.org/10.17763/haer.81.2. 92315ww157656k3u.

Foor, C. E., Walden, S. E., \& Trytten, D. A. (2007). "I wish that I belonged more in this whole engineering group:" Achieving individual diversity. Journal of Engineering Education, 96(2), 103-115. https://doi.org/10.1002/j.2168-9830.2 007.tb00921.x. 
Fornell, C., \& Larcker, D. F. (1981). Evaluating structural equation models with unobservable variables and measurement error. Journal of Marketing Research, 18(1), 39. https://doi.org/10.2307/3151312.

Gardner, D. G., Cummings, L. L., Dunham, R. B., \& Pierce, J. L. (1998). Single-item versus multiple-item measurement scales An empirical comparison. Educational and Psychological Measurement, 58(6), 898-915. https://doi.org/1 $0.1177 / 0013164498058006003$

Gee, J. P. (2001). Identity as an analytic lens for research in education. In W. G. Secada (Ed.), Review of research in education, (vol. 25, pp. 99-126). https://doi. org/10.3102/0091732X025001099.

Geisinger, B. N., \& Raman, D. R. a. J. (2013). Why they leave: Understanding student attrition from engineering majors. International Journal of Engineering Education, 29(4), 914-925.

Godwin, A. (2016). The development of a measure of engineering identity. In Paper presented at 2016 ASEE annual conference \& exposition, New Orleans, Louisiana. https://doi.org/10.18260/p.26122.

Godwin, A., \& Kirn, A. (2020). Identity-based motivation: Connections between firstyear students' engineering role identities and future-time perspectives. Journal of Engineering Education, 109(3), 362-383. https://doi.org/10.1002/jee.20324.

Godwin, A., \& Potvin, G. (2017). Pushing and pulling Sara: A case study of the contrasting influences of high school and university experiences on engineering agency, identity, and participation. Journal of Research in Science Teaching, 54(4), 439-462. https://doi.org/10.1002/tea.21372.

Godwin, A., Potvin, G., Hazari, Z., \& Lock, R. (2016). Identity, critical agency, and engineering: An affective model for predicting engineering as a career choice. Journal of Engineering Education, 105(2), 312-340. https://doi.org/10.1 002/jee.20118.

Goodenow, C. (1993). Classroom belonging among early adolescent students: Relationships to motivation and achievement. Journal of Early Adolescence, 13(1), 21-43. https://doi.org/10.1177/0272431693013001002.

Goodman, D. J. (2011). Promoting diversity and social justice: Educating people from privileged groups. Routledge. https://doi.org/10.4324/9780203829738.

Gusa, D. L. (2010). White institutional presence: The impact of whiteness on campus climate. Harvard Educational Review, 80(4), 464-489. https://doi.org/1 0.17763/haer.80.4.p5j483825u1 10002 .

Hackett, G., Betz, N. E., Casas, J., \& Rocha-Singh, I. (1992). Gender, ethnicity and social cognitive factors predicting achievement. Journal of Counseling Psychology, 39(4), 527-538. https://doi.org/10.1037/0022-0167.39.4.527.

Hartung, P. J. (1995). Assessing career certainty and choice status. ERIC Digest https://files.eric.ed.gov/fulltext/ED391107.pdf.

Hazari, Z., Chari, D., Potvin, G., \& Brewe, E. (2020). The context dependence of physics identity: Examining the role of performance/competence, recognition, interest, and sense of belonging for lower and upper female physics undergraduates. Journal of Research in Science Teaching, 2019(10), 125. https://doi.org/10.1002/tea.21644.

Hazari, Z., Sonnert, G., Sadler, P. M., \& Shanahan, M. C. (2010). Connecting high school physics experiences, outcome expectations, physics identity, and physics career choice: A gender study. Journal of Research in Science Teaching, 47(8), 978-1003. https://doi.org/10.1002/tea.20363.

Hidi, S., \& Renninger, K. A. (2006). The four-phase model of interest development. Educational Psychologist, 41(2), 87-98. https://doi.org/10.1207/s15326985ep4102.

Hoeppner, B. B., Kelly, J. F., Urbanoski, K. A., \& Slaymaker, V. (2011). Comparative utility of a single-item vs. multiple-item measure of self-efficacy in predicting relapse among young adults Bettina. Journal of Substance Abuse Treatment, 41(3), 305-312. https://doi.org/10.1016/j.jsat.2011.04.005.Comparative.

Holland, D. G. (2019). The struggle to belong and thrive. In E. Seymour, \& A. B. Hunter (Eds.), Talking about leaving revisited: Persistence, relocation, and loss in undergraduate STEM education, (pp. 277-327). Springer. https://doi.org/10.1 007/978-3-030-25304-2_9.

Hu, L., \& Bentler, P. M. (1999). Cutoff criteria for fit indexes in covariance structure analysis: Conventional criteria versus new alternatives. Structural Equation Modeling: A Multidisciplinary Journal, 6(1), 1-55. https://doi.org/10.1080/1 0705519909540118

Hurtado, S., \& Carter, D. F. (1997). Effects of college transition and perceptions of the campus racial climate on Latino college students' sense of belonging. Sociology of Education, 70(4), 324-345. https://doi.org/10.2307/2673270.

Johnson, D. R., Soldner, M., Leonard, J. B., Alvarez, P., Inkelas, K. K., RowanKenyon, H. T., \& Longerbeam, S. D. (2007). Examining sense of belonging among first-year undergraduates from different racial/ethnic groups. Journal of College Student Development, 48(5), 525-542. https://doi.org/1 $0.1353 /$ csd.2007.0054
Jones, B. D., Ruff, C., \& Paretti, M. C. (2013). The impact of engineering identification and stereotypes on undergraduate women's achievement and persistence in engineering. Social Psychology of Education, 16(3), 471-493. https://doi.org/10.1007/s11218-013-9222-x.

Jorgenson, J. (2002). Engineering selves negotiating gender and identity in technical work. Management Communication Quarterly, 15(3), 350-380. https://doi.org/10.1177/0893318902153002.

Kline, R. B. (2016). Principles and practices of structurla equation modeling, (4th ed., ). The Guilford Press.

Larson, W. (2000). Toward a psychology of positive youth development. American Psychologist, 55(1), 170-183. https://doi.org/10.1037//0003-066X.

Lee, H. S., Flores, L. Y., Navarro, R. R., \& Kanagui-Muñoz, M. (2015). A longitudinal test of social cognitive career theory's academic persistence model among Latino/a and White men and women engineering students. Journal of Vocational Behavior, 88, 95-103. https://doi.org/10.1016/j.jvb.2015.02.003.

Lent, R., Brown, S. D., \& Hackett, G. (1994). Toward a unifying scct and academic interest, choice and performance. Journal of Vocational Behavior, 45(1), 79122. https://doi.org/10.1177/1069072716657811

Lent, R. W., Brown, S. D., \& Larkin, K. C. (1986). Self-efficacy in the prediction of academic performance and perceived career options. Journal of Counseling Psychology, 33(3), 265-269. https://doi.org/10.1037/0022-0167.33.3.265.

Lent, R. W., Brown, S. D., Schmidt, J., Brenner, B., Lyons, H., \& Treistman, D. (2003). Relation of contextual supports and barriers to choice behavior in engineering majors: Test of alternative social cognitive models. Journal of Counseling Psychology, 50(4), 458-465. https://doi.org/10.1037/0022-0167.50.4.458.

Lomax, R. G., \& Schumacker, R. E. (2004). A beginner's guide to structural equation modeling. Routledge.

Maestas, R., Vaquera, G. S., \& Zehr, L. M. (2007). Factors impacting sense of belonging at a Hispanic-serving institution. Journal of Hispanic Higher Education, 6(3), 237-256. https://doi.org/10.1177/1538192707302801.

Marra, R. M., Rodgers, K. A., Shen, D., \& Bogue, B. (2012). Leaving engineering: A multi-year single institution study. Journal of Engineering Education, 101(1), 627. https://doi.org/10.1002/j.2168-9830.2012.tb00039.x.

McGee, E. O. (2016). Devalued black and latino racial identities. American Educational Research Journal, 53(6), 1626-1662. https://doi.org/10.3102/0002 831216676572

Meyers, K. L., Ohland, M. W., Pawley, A. L., Silliman, S. E., \& Smith, K. A. (2012). Factors relating to engineering identity. Global Journal of Engineering Education, 14(1), 119-131.

Micceri, T. (1989). The unicorn, the normal curve, and other improbable creatures. Psychological Bulletin, 105(1), 156-166. https://doi.org/10.1037/0033-2909.1 05.1.156.

Multon, K. D., Brown, S. D., \& Lent, R. W. (1991). Relation of self-efficacy beliefs to academic outcomes: A meta-analytic investigation. Journal of Counseling Psychology, 38(1), 30-38. https://doi.org/10.1037/0022-0167.38.1.30.

Museus, S. D. (2013). Asian Americans and Pacific Islanders. In The misrepresented minority: New insights on Asian Americans and Pacific Islanders, and the implications for higher education. Stylus Publishing.

Museus, S. D., \& Kiang, P. N. (2009). Deconstructing the model minority myth and how it contributes to the invisible minority reality in higher education research. New Directions for Institutional Research, 2009(142), 5-15. https://doi. org/10.1002/ir.292.

Museus, S. D., Ledesma, M. C., \& Parker, T. L. (2015). Racism and racial equity in higher education. In ASHE higher education report (Vol. 42, Issue 1). https://doi. org/10.1002/aehe.20067.

Museus, S. D., Yi, V., \& Saelua, N. (2017). The impact of culturally engaging campus environments on sense of belonging. Review of Higher Education, 40(2), 187-215. https://doi.org/10.1353/rhe.2017.0001.

National Science Foundation, \& National Center for Science and Engineering Statistics. (2017). Women, minorities, and persons with disabilities in science and engineering. https:/www.nsf.gov/statistics/2017/nsf17310/static/ downloads/nsf17310-digest.pdf

National Science Foundation, \& National Center for Science and Engineering Statistics (2019a). Demographic characteristics of employed scientists and engineers, by sex: 2017. In Women, minorities, and persons with disabilities in science and engineering.

National Science Foundation, \& National Center for Science and Engineering Statistics (2019b). Science, engineering, and health doctorate holders employed in universities and 4-year colleges, by broad occupation, race, ethnicity, and faculty rank: 2017. In Women, minorities, and persons with disabilities in science and engineering. 
National Science Foundation, \& National Center for Science and Engineering Statistics. (2019c). Women, minorities, and persons with disabilities in science and engineering. www.nsf.gov/statistics/wmpd/.

National Science Foundation, \& National Center for Science and Engineering Statistics (2019d). Women, minorities, and persons with disabilities in science and engineering. In Special report NSF https://doi.org/Special Report NSF 11-309.

Neal-Jackson, A. (2018). A meta-ethnographic review of the experiences of African American girls and young women in $\mathrm{K}-12$ education. Review of Educational Research, 88(4), 508-546. https://doi.org/10.3102/003465431 8760785.

Ong, M., Wright, C., Espinosa, L. L., \& Orfield, G. (2011). Inside the double bind: A synthesis of empirical research on undergraduate and graduate women of color in science, technology, engineering, and mathematics. Harvard Educational Review, 81(2), 172-208. https://doi.org/10.17763/haer.81.2.t02224 $5 n 7 \times 4752 v 2$.

Osterman, K. F. (2000). Students' need for belonging in the school community. Review of Educational Research, 70(3), 323-367. https://doi.org/10.3102/0034 6543070003323.

Oyserman, D. (2015). Identity-based motivation. In R. Scott, \& S. Kosslyn (Eds.), Emerging trends in the social and behavioral science, (pp. 1-11). Wiley.

Oyserman, D., \& James, L. (2011). Possible identities. In S. J. Schwartz (Ed.), Handbook of identity theory and research, (pp. 117-145). Springer Science \& Business Media. https://doi.org/10.1007/978-1-4419-7988-9_6.

Pajares, F. (1996). Self-efficacy beliefs in academic settings. Review of Educational Research, 66(4), 543-578. https://doi.org/10.3102/00346543066004543.

Pajares, F. (1997). Current directions in self-efficacy. In M. Maehr, \& P. R. Pintrich (Eds.), Advances in motivation and achievement, (vol. 10, pp. 1-49). JAI Press.

Patrick, A. D., Borrego, M., \& Prybutok, A. N. (2018). Predicting persistence in engineering through an engineering identity scale. International Journal of Engineering Education, 34(2), 351-363.

Pierrakos, O., Beam, T. K., Constantz, J., Johri, A., \& Anderson, R. (2009). On the development of a professional identity: Engineering persistors vs. engineering switchers. Frontiers in Education Conference, 39(2), 599-604. https://doi.org/10.1109/FIE.2009.5350571.

Potvin, G., \& Hazari, Z. (2013). The development and measurement of identity across the physical sciences. In PERC proceedings, (pp. 281-284). https://doi. org/10.1119/perc.2013.pr.058.

R Core Team (2019). R: A language and environment for statistical computing. $R$ Foundation for Statistical Computing https://www.R-project.org/.

Rainey, K., Dancy, M., Mickelson, R., Stearns, E., \& Moller, S. (2018). Race and gender differences in how sense of belonging influences decisions to major in STEM. International Journal of STEM Edudcation, 5(10). https://doi.org/10.11 86/s40594-018-0115-6.

Rainey, A. Verdín, D. \& Smith, J. (2021) Classroom practices that support minoritized engineering students' sense of belonging. Paper presented at 2021 ASEE Virtual Annual Conference Content Access, Virtual Online.

Reason, R. D., \& Evans, N. J. (2007). The complicated realities of whiteness: From color blind to racially cognizant. New Directions for Student Services, 2007(120), 67-75. https://doi.org/10.1002/ss.258.

Renninger, A., Nieswandt, M., \& Hidi, S. (2015). Interest in mathematics and science learning. American Educational Research Association. https://doi.org/10.3102/ 978-0-935302-42-4

Renninger, K. A. (2009). Interest and identity development in instruction: An inductive model. Educational Psychologist, 44(2), 105-118. https://doi.org/10.1 080/00461520902832392.

Renninger, K. A., \& Hidi, S. (2002). Student interest and achievement: Developmental issues raised by a case study. In A. Wigfield, \& J. S. Eccles (Eds.), Development of achievement motivation, (pp. 167-187). Oxford University Press. https://doi.org/10.1093/oxfordhb/9780195399820.013.0011.

Renninger, K. A., \& Su, S. (2012). Interest and its development. In R. M. Ryan (Ed.), The Oxford handbook of human motivation, (pp. 173-195). Academic.

Rohde, J. A., Verdin, D., Doyle, J., Godwin, A., Kirn, A., Benson, L., \& Potvin, G. (2019). Investigating the intersection of career aspirations and engineering beliefs in first year engineering students. In Proceedings - Frontiers in Education Conference, FIE, 2018-October, (p. 1428689). https://doi.org/10.1109/ FIE.2018.8659311.

Rosseel, Y. (2012). lavaan: An R package for structural equation. Journal of Statistical Software, 48(2), 1-36. https://doi.org/10.18637/jss.v048.i02.

Roy, J. (2018). Engineering by the numbers. American Society for Engineering Education, 11-47 https://ira.asee.org/wp-content/uploads/2019/07/2018Engineering-by-Numbers-Engineering-Statistics-UPDATED-15-July-2019.pdf.
Sass, D. A., \& Schmitt, T. A. (2013). Testing measurement and structural invariance. In T. Teo (Ed.), Handbook of quantitative methods for educational research, (pp. 315-345). Sense Publishers. https://doi.org/10.1007/978-94-6209-404-8_15.

Satorra, A., \& Bentler, P. M. (2010). Ensuring possitiveness of the scaled difference chi-square test statistic. Psychometrika, 75(2), 243-248. https://doi.org/10.1 007/s11336-009-9135-y.

Secules, S., Gupta, A., Elby, A., \& Tanu, E. (2018). Supporting the narrative agency of a marginalized engineering student. Journal of Engineering Education, 107(2), 186-218. https://doi.org/10.1002/jee.20201.

Seymour, E., \& Hewitt, N. M. (1997). Talking about leaving: Why undergraduates leave the sciences. Westview Press.

Seymour, E., \& Hunter, A. B. (2019). Talking about leaving revisited: Persistence, relocation, and loss in undergraduate STEM education. Springer. https://doi. org/10.1007/978-3-030-25304-2.

Slaton, A. (2015). Meritocracy, technocracy, democracy: Understandings of racial and gender equity in American engineering education. In International perspectives on engineering education, (pp. 171-189). Springer International Publishing Switzerland.

Smith, J. M., \& Lucena, J. C. (2016). Invisible innovators: How low-income, firstgeneration students use their funds of knowledge to belong in engineering. Engineering Studies, 8(1), 1-26. https://doi.org/10.1080/19378629.2016.11 55593

Smith, T. F., Wilson, D., Jones, D. C., Plett, M., Bates, R. A., \& Veilleux, N. M. (2012). Investigation of belonging for engineering and science undergraduates by year in school. In Paper presented at 2012 ASEE annual conference \& exposition, San Antonio, Texas. https://doi.org/10.18260/1-2-21615.

Stevens, R., O'connor, K., Garrison, L., Jocuns, A., \& Amos, D. M. (2008). Becoming an engineer: Toward a three dimensional view of engineering learning. Journal of Engineering Education, 97(3), 355-368. https://doi.org/10.1002/j.21 68-9830.2008.tb00984.x.

Strayhorn, T. L. (2018). College students' sense of belonging: A key to educational success for all students. Routledge. https://doi.org/10.4324/9781315297293.

Tabachnick, B. G., \& Fidell, L. S. (2013). Using multivariate statistics, (6th ed., ). Pearson Education Inc.

Tate, E. D., \& Linn, M. C. (2005). How does identity shape the experiences of women of color engineering students? Journal of Science Education and Technology, 14(5-6), 483-493. https://doi.org/10.1007/s10956-005-0223-1.

Tavakol, M., \& Dennick, R. (2011). Making sense of Cronbach's alpha. International Journal of Medical Education, 2, 53-55. https://doi.org/10.5116/ijme.4dfb.8dfd.

Tonso, K. L. (1996). The impact of cultural norms on women. Journal of Engineering Education, 85(3), 217-225. https://doi.org/10.1002/j.2168-9830.1 996.tb00236.x.

Tonso, K. L. (1999). Engineering gender- gendering engineering: A cultural model for belonging. Journal of Women and Minorities in Science and Engineering, 5(4), 365-405. https://doi.org/10.1615/JWomenMinorScienEng.v5.i4.60.

Tonso, K. L. (2006a). Student engineers and engineer identity: Campus engineer identities as figured world. Cultural Studies of Science Education, 1(2), 273-307. https://doi.org/10.1007/s11422-005-9009-2.

Tonso, K. L. (2006b). Teams that work: Campus culture, engineering identity, and social interactions. Journal of Engineering Education, 95(1), 25-37. https://doi. org/10.1002/j.2168-9830.2006.tb00875.x.

Tonso, K. L. (2007). On the outskirts of engineering: Learning identity, gender, and power via engineering practice. Sense Publishing. https://doi.org/10.1163/ 9789087903534.

Vaccaro, A., \& Newman, B. M. (2016). Development of a sense of belonging for privileged and minoritized students: An emergent model. Journal of College Student Development, 57(8), 925-942. https://doi.org/10.1353/csd.2016.0091.

Vaz, S., Falkmer, M., Ciccarelli, M., Passmore, A., Parsons, R., Tan, T., \& Falkmer, T. (2015). The personal and contextual contributors to school belongingness among primary school students. PLoS One, 10(4), e0123353. https://doi.org/1 0.1371/journal.pone.0123353.

Verdín, D. (2021). Negotiating belongingness: A longitudinal narrative inquiry of a Latina, first-generation college student's experience in the engineering culture. In Paper presented at 2021 ASEE virtual annual conference content access, virtual online In press.

Verdín, D., \& Godwin, A. (2017a). Physics identity promotes alternative careers for first-generation college students in engineering. In Paper presented at 2017 ASEE annual conference \& exposition, Columbus, Ohio. https://doi.org/10.182 $60 / 1-2-28741$

Verdín, D., \& Godwin, A. (2017b). Testing for measurement invariance in engineering identity constructs for first-generation college students. In 
Proceedings - Frontiers in Education Conference, FIE, 2017-Octob, 1-5. https:// doi.org/10.1109/FIE.2017.8190616.

Verdín, D., \& Godwin, A. (2018a). Exploring Latina first-generation college students' multiple identities, self-efficacy, and institutional integration to inform achievement in engineering. Journal of Women and Minorities in Science and Engineering, 24(3), 261-290. https://doi.org/10.1615/ JWOMENMINORSCIENENG.2018018667.

Verdín, D., \& Godwin, A. (2018b). First-generation college students identifying as future engineers. In Paper presented at the 2018 annual meeting of the American educational research association https://doi.org/10.302/1300654.

Verdín, D., Godwin, A., Kirn, A., Benson, L., \& Potvin, G. (2018). Understanding how engineering identity and belongingness predict grit for first-generation college students. In Paper presented at 2018 CoNECD - The Collaborative Network for Engineering and Computing Diversity Conference, Crystal City, Virginia https://peer.asee.org/29589.

Verdín, D., Godwin, A., Kirn, A., Benson, L., \& Potvin, G. (2019). Engineering role identity fosters grit differently for women first- and continuing-generation college students. International Journal of Engineering Education, 35(4), 1037-1051.

Verdín, D., Godwin, A., \& Ross, M. (2018). STEM Roles: How students' ontological perspectives facilitate STEM identities. Journal of Pre-College Engineering Education Research, 8(2). https://doi.org/10.7771/2157-9288.1167.

Verdín, D., Godwin, A., Sonnert, G., \& Sadler, P. M. (2018). Understanding how first-generation college students' out-of-school experiences, physics and STEM identities relate to engineering possible selves and certainty of career path. In Proceedings - Frontiers in Education Conference, FIE. https://doi.org/1 0.1109/FIE.2018.8658878.

Verdín, D., Smith, J. M., \& Lucena, J. C. (2019). Recognizing engineering students' funds of knowledge: Creating and validating survey measures. In Paper presented at 2019 ASEE annual conference \& exposition, Tampa, Florida. https:// doi.org/10.18260/1-2-33226.

Verdín, D., Smith, J. M., \& Lucena, J. C. (2020). The influence of connecting funds of knowledge to beliefs about performance, classroom belonging, and graduation certainty for first-generation college students. In Paper presented at 2020 ASEE virtual annual conference content access, virtual online. https:// doi.org/10.18260/1-2-35343.

Walton, G. M., \& Cohen, G. L. (2007). A question of belonging: Race, social fit, and achievement. Journal of Personality and Social Psychology, 92(1), 82-96. https://doi.org/10.1037/0022-3514.92.1.82.

Watts, J. H. (2009). "Allowed into a man's world" meanings of work-life balance: Perspectives of women civil engineers as "minority" workers in construction. Gender, Work and Organization, 16(1), 37-57. https://doi.org/10.1111/j.14680432.2007.00352.X.

West, S. G., Finch, J. F., \& Curran, P. J. (1995). Structural equation models with nonnormal variables: Problems and remedies. In R. H. Hoyle (Ed.), Structural equation modeling: Concepts, issues, and applications, (pp. 56-75). Sage Publications, Inc.

Wilson, D., Jones, D., Bocell, F., Crawford, J., Kim, M. J., Veilleux, N., ... Plett, M. (2015). Belonging and academic engagement among undergraduate STEM students: A multi-institutional study. Research in Higher Education, 56(7), 750776. https://doi.org/10.1007/s11162-015-9367-x.

Yoder, B. L. (2017). Engineering by the numbers. American Society for Engineering Education.

\section{Publisher's Note}

Springer Nature remains neutral with regard to jurisdictional claims in published maps and institutional affiliations.

\section{Submit your manuscript to a SpringerOpen ${ }^{\circ}$ journal and benefit from:}

- Convenient online submission

- Rigorous peer review

- Open access: articles freely available online

- High visibility within the field

- Retaining the copyright to your article

Submit your next manuscript at $\boldsymbol{\nabla}$ springeropen.com 